\title{
Protein phosphatase 6 is a key factor regulating spermatogenesis
}

\author{
Wen-Long Lei ${ }^{1,2} \cdot$ Feng Han $\mathbb{D}^{1,3} \cdot$ Meng-Wen Hu${ }^{1} \cdot$ Qiu-Xia Liang ${ }^{1,4} \cdot$ Tie-Gang Meng ${ }^{1,2} \cdot$ Qian Zhou ${ }^{1,2} \cdot$

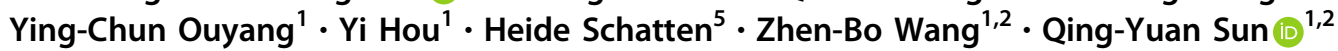

Received: 6 June 2019 / Accepted: 27 November 2019 / Published online: 9 December 2019

(c) The Author(s), under exclusive licence to ADMC Associazione Differenziamento e Morte Cellulare 2019

\begin{abstract}
Protein phosphatase 6 (PP6) is a member of the PP2A-like subfamily, which plays a critical role in many fundamental cellular processes. We recently reported that PP6 is essential for female fertility. Here, we report that PP6 is involved in meiotic recombination and that germ cell-specific deletion of PP6 by Stra8-Cre causes defective spermatogenesis. The PP6deficient spermatocytes were arrested at the pachytene stage and defects in DSB repair and crossover formation were observed, indicating that PP6 facilitated meiotic double-stranded breaks (DSB) repair. Further investigations revealed that depletion of PP6 in the germ cells affected chromatin relaxation, which was dependent on MAPK pathway activity, consequently preventing programmed DSB repair factors from being recruited to proper positions on the chromatin. Taken together, our results demonstrate that PP6 has an important role in meiotic recombination and male fertility.
\end{abstract}

\section{Introduction}

Spermatogenesis is a complex developmental process by which male germline stem cells divide and differentiate to

Edited by H.-U. Simon

Supplementary information The online version of this article (https:// doi.org/10.1038/s41418-019-0472-9) contains supplementary material, which is available to authorized users.

Zhen-Bo Wang

wangzb@ioz.ac.cn

$\triangle$ Qing-Yuan Sun

sunqy@ioz.ac.cn

1 State Key Laboratory of Stem Cell and Reproductive Biology, Institute of Zoology, Chinese Academy of Sciences, Beijing 100101, China

2 University of Chinese Academy of Sciences, Beijing 100101, China

3 Key Laboratory for Major Obstetric Diseases of Guangdong Province, Key Laboratory of Reproduction and Genetics of Guangdong Higher Education Institutes, The Third Affiliated Hospital of Guangzhou Medical University, Guangzhou 510150, China

4 Department of Reproductive Medicine, Peking University Shenzhen Hospital, Shenzhen, Guangdong 518036, China

5 Department of Veterinary Pathobiology, University of Missouri, Columbia, MO 65211, USA produce mature spermatozoa. In mammalian testes, this process occurs within seminiferous tubules and consists of three phases: mitosis, meiosis, and spermiogenesis [1]. In the second phase of spermatogenesis, meiosis is characterized by chromosome recognition, pairing, synapsis, recombination, and segregation of homologous chromosomes [2]. Meiosis I is different from meiosis II and mitosis in that it involves the exchange of genetic materials during prophase I [3]. This phase is subdivided into leptotene, zygotene, pachytene, diplotene, and diakinesis. Recombination is initiated at the leptotene stage by the formation of double-stranded breaks (DSBs) [4]. DSBs activate the ATM kinase, which performs an essential role in controlling DSB numbers via a negative feedback loop and plays an essential role in shaping DSB distribution across the genome [5, 6]. Any mistake in meiotic recombination can lead to meiotic arrest or chromosome segregation failure, resulting in severe consequences including infertility [7, 8].

Protein phosphorylation and dephosphorylation are essential for spermatogenesis [9]. Changes in the phosphorylation status are mediated by a conserved cohort of protein kinases and phosphatases. For various reasons, protein phosphatases have been much less studied than protein kinases. Among the phosphoprotein phosphatases, PP2A, PP4, and PP6 comprise the type 2 A subfamily within the serine/threonine phosphatase gene family [10]. These enzymes play vital roles in multiple aspects of fundamental cellular signal processes [11]. Among type $2 \mathrm{~A}$ 
protein phosphatases, PP2A is the best known and is extensively studied. PP2A is involved in cell proliferation, signal transduction, DNA repair, and apoptosis [12]. We previously reported that PP2A has an indispensable role in oocyte meiotic maturation, though it is dispensable for folliculogenesis in the mouse ovary [13]. PP4 has been implicated in microtubule organization, histone modifications, DNA damage responses, and signal transduction [14-17]. Although abundantly expressed in cells with multiple roles in cellular signaling, PP6 has received less attention than its close relative PP2A and PP4.

Like other type 2 A Ser/Thr protein phosphatases, PP6 works as a holoenzyme, with regulatory subunits that are evolutionally conserved among eukaryotes, suggesting its fundamental importance. It has been found that mutations in PP6 exist in 9-12.4\% melanomas surveyed and PP6 might act as a driver for melanoma development [18, 19]. More recent studies suggested an important role for PP6 in cell/ organ size regulation through the Hippo pathway, inflammatory signaling and pre-mRNA splicing [20-22]. PP6 has been found to play a vital role in the G1-S transition and S phase arrest [23-25], as well as in regulating mitotic spindle formation and chromosome segregation by controlling the T-loop phosphorylation state of Aurora A bound to its activator TPX2 [26]. It is also suggested that PP6 is recruited to sites of DNA damage where PP6 may contribute to the dephosphorylation of $\gamma$-H2AX [27].

Our laboratory recently reported that a conditional knockout of PP6 in oocytes from growing follicles (by crossing Ppp6c ${ }^{F / F}$ mice with $\mathrm{Zp3}$-Cre mice) caused female subfertility by disrupting the second meiosis completion [28], and specific deletion of Ppp6c in Ppp6c ${ }^{F / F} ;$ Gdf9-Cre oocytes from the primordial follicle stage, caused female infertility owing to persistent phosphorylation of $\mathrm{H} 2 \mathrm{AX}$ in oocytes, which leads to massive elimination of oocytes and premature ovarian failure [29]. Here, we crossed $P p p 6 c^{F / F}$ mice with Stra8-Cre mice to generate mutant mice with specific deletion of the Ppp6c gene in male germ cells. We found that the PPP6c-deficient male mice were completely infertile and germ cells were arrested at the pachytene stage during spermatogenesis. Further investigation revealed that the depletion of PP6 in germ cells affected chromatin relaxation, which was dependent on MAPK pathway activity, thus preventing the recruitment of programmed DSB repair factors to the proper positions on chromosomes.

\section{Materials and methods}

\section{Mice}

Mice lacking Ppp6c in male germ cells (referred to as $P p p 6 c^{c K O}$ ) were generated by crossing $P p p 6 c^{F / F}$ mice with
Stra8-Cre mice. Both transgenic mouse lines have C57BL/ $6 \mathrm{~J}$ genomic background. The $P p p 6 c^{W T}$ male mice were used as control group. Genotyping PCR for Ppp6c was performed using the following primers: forward: GCAGAGGATGGGGTCACATAG, and reverse: ATCTCTGAACCAATTCTGGAG. The PCR conditions were as follows: $94{ }^{\circ} \mathrm{C}$ for $5 \mathrm{~min}$; 35 rounds of $94{ }^{\circ} \mathrm{C}$ for $30 \mathrm{sec}$, $56{ }^{\circ} \mathrm{C}$ for $30 \mathrm{sec}$, and $72{ }^{\circ} \mathrm{C}$ for $30 \mathrm{sec}$; and $72{ }^{\circ} \mathrm{C}$ for $5 \mathrm{~min}$. Genotyping PCR for Stra8-Cre was performed using the following primers: forward: GTGCAAGCTGAACAACAGGA, and reverse: AGGGACACAGCATTGGAGTC. The PCR conditions were as follows: $94^{\circ} \mathrm{C}$ for $5 \mathrm{~min}$; 35 rounds of $94{ }^{\circ} \mathrm{C}$ for $30 \mathrm{sec}, 66^{\circ} \mathrm{C}$ for $30 \mathrm{sec}$, and $72{ }^{\circ} \mathrm{C}$ for $30 \mathrm{sec}$; and $72{ }^{\circ} \mathrm{C}$ for $5 \mathrm{~min}$.

The mice were housed under controlled environmental conditions with free access to water and food. All animal operations were approved by the Animal Research Committee principles of the Institute of Zoology, Chinese Academy of Sciences.

\section{Antibodies}

PPP6C (rabbit, A300-844A; Bethyl Laboratories, Inc.); SYCP3 (rabbit, NB300-231; Novus Biologicals); $\beta$-actin antibody (mouse, sc-47778; Santa Cruz); SYCP3 (mouse, sc-74569; Santa Cruz); $\gamma \mathrm{H} 2 \mathrm{AX}$ (rabbit, 9718; Cell Signaling Technology, Inc.); Phospho-ATM (mouse, 4526; Cell Signaling Technology, Inc.); p44/42 MAPK (Erk1/2) (rabbit, 4695; Cell Signaling Technology, Inc.); Phospho-p44/ 42 MAPK (Erk1/2) (Thr202/Tyr204) (rabbit, 4377; Cell Signaling Technology, Inc.); MVH (mouse, ab27591; abcam); SYCP1 (rabbit, ab15090; abcam); MLH1 (mouse, ab14206; abcam); H3 dimethyl-K9 (rabbit, 07-212; Upstate); Histone H3K14ac (rabbit, BE3225; Easybio); Tak1 (phospho Thr187) (rabbit, YP0424; Immunoway); TAK1 Antibody (rabbit, 12330-2-AP; Proteintech); HMGA2 Antibody (rabbit, 20795-1-AP; Proteintech); HATag mab (mouse, AE008; ABclonal); c-Myc antibody (mouse, m4439; sigma); MRE11 (rabbit) and DMC1 (rabbit) were gifted from Mengcheng Luo. Horseradish peroxidase-conjugated secondary antibodies were purchased from Zhongshan Golden Bridge Biotechnology Co, LTD (Beijing). Alexa Fluor 488-conjugated antibody and Alexa Fluor 594-conjugated antibody were purchased from Life Technologies.

\section{Breeding assay}

Males of different genotypes (8-9 weeks) were used for the breeding assay. Each male mouse was caged with two wild-type C57BL/6 J females (7-8 weeks), and their vaginal plugs were checked every morning. The number of pups in each cage was counted within a week of birth. 
Each male underwent six cycles of the above breeding assay.

\section{Immunoblotting}

To prepare protein extracts, testis extracts were prepared using a homogenizer in radioimmunoprecipitation assay (RIPA) buffer supplemented with protease and phosphatase inhibitor cocktail (Roche Diagnostics). Germ cell isolated from testes were resuspended in cold RIPA buffer as described above. After transient ultrasound, the testis lysates or germ cell lysates were incubated on ice for $30 \mathrm{~min}$ and then centrifuged at $4{ }^{\circ} \mathrm{C}, 12,000 \mathrm{rpm}$ for $20 \mathrm{~min}$. The supernatant was transferred to a new tube and equal volume loading buffer was added. After being boiled at $95^{\circ} \mathrm{C}$ for $10 \mathrm{~min}$, the protein lysates were used for immunoblotting analysis. Immunoblotting was performed as described previously [30]. In brief, the separated proteins in sodium dodecyl sulfate-polyacrylamide gel electrophoresis (SDSPAGE) were electrically transferred to a polyvinylidene fluoride membrane. After incubation with primary and secondary antibodies, the membranes were scanned with Bio-Rad ChemiDoc XRS+.

\section{Tissue collection and histological analysis}

For histological examination, at least three adult mice for each genotype were analyzed. Testes and caudal epididymides were dissected immediately following euthanasia. The tissues were then fixed in Bouin's fixative overnight at room temperature, dehydrated in an ethanol series, and embedded in paraffin wax. Then, $5 \mu \mathrm{m}$ sections were cut with a microtome. After $48^{\circ} \mathrm{C}$ overnight drying, the sections were deparaffinized in xylene, hydrated by a graded alcohol series and stained with hematoxylin and eosin for histological analysis, or stained with periodic acid schiff (PAS)-hematoxylin for determining the seminiferous epithelia cycle stages. Images were collected with a Nikon inverted microscope with a charge coupled device (Nikon, Eclipse Ti-S, Tokyo, Japan).

\section{Immunofluorescence}

Testes used for immunostaining were fixed in $4 \%$ paraformaldehyde ( $\mathrm{pH} 7.4$ ) overnight at $4{ }^{\circ} \mathrm{C}$, dehydrated, and embedded in paraffin. Paraffin-embedded testes were cut into sections of 5- $\mu \mathrm{m}$ thickness. Then, the sections were deparaffinized, immersed in sodium citrate buffer $(\mathrm{pH} 6.0)$ and heated for $15 \mathrm{~min}$ in a microwave for antigen retrieval. After blocking with $5 \%$ donkey serum albumin, sections were incubated with primary antibodies at $4{ }^{\circ} \mathrm{C}$ overnight. Then the sections were incubated with an appropriate fluorescein isothiocyanate-conjugated secondary antibody.
The nuclei were stained with $4^{\prime}, 6$-diamidino-2-phenylindole. Images were captured using a laser scanning confocal microscope (Zeiss 780 META).

\section{TUNEL assay}

Terminal deoxynucleotidyl transferase dUTP nick end labeling (TUNEL) assay was carried out in accordance with the DeadEnd Fluorometric TUNEL System (Promega BioSciences, Madison, WI, USA). Images were captured using a laser scanning confocal microscope (Zeiss 780 META).

\section{Spermatocyte surface spreading}

Spermatocyte surface spreading was performed according to the drying-down technique as previously described [31]. In brief, testes were dissected and the tubules were washed in phosphate-buffered saline (PBS) $\mathrm{pH} 7.4$ at room temperature. Next, the tubules were submerged in a hypotonic extraction buffer (30 mM Tris $\mathrm{pH} 8.2,50 \mathrm{~mm}$ sucrose, $17 \mathrm{~mm}$ trisodium citrate dihydrate, $5 \mathrm{~mm}$ ethylenediaminetetraacetic acid, $0.5 \mathrm{~mm}$ dithiothreitol, and $0.5 \mathrm{~mm}$ phenylmethylsulfonyl fluoride) for $30-45 \mathrm{~min}$. Subsequently, the tubules were torn into pieces in $100 \mathrm{~mm}$ sucrose $\mathrm{pH} 8.2$ on a clean glass slide and then pipetted gently to make a suspension. The cell suspensions were loaded on slides containing $1 \%$ paraformaldehyde $\mathrm{pH} 9.2$ and $0.15 \%$ Triton $\mathrm{X}-100$. The slides were dried overnight. Finally, the slides were washed with PBS for $10 \mathrm{~min}$ and immunostained with antibodies according to the standard protocols mentioned above.

\section{Isolation of mouse germ cells}

Spermatogenic cells were isolated using a protocol previously described by Bellve with minor modification [32] In brief, testes from adult $P p p 6 c^{W T}$ and $P p p 6 c^{c K O}$ mice were removed and decapsulated. The seminiferous tubules were torn into small pieces and incubated in $4.5 \mathrm{ml}$ PBS containing $1 \mathrm{mg} / \mathrm{ml}$ collagenase (Sigma, C5138, St. Louis, MO, USA) and $1 \mathrm{mg} / \mathrm{ml}$ DNase I (Solarbio, D8071) at $37^{\circ} \mathrm{C}$ for 5 min with gentle shaking. Then, the cells were collected by centrifugation at $200 \times g$ for $1 \mathrm{~min}$ at $4{ }^{\circ} \mathrm{C}$. Next, the cells were incubated in $4.5 \mathrm{ml} 0.25 \%$ Trypsin and $1 \mathrm{mg} / \mathrm{ml}$ DNase I, and incubated at $37{ }^{\circ} \mathrm{C}$ for 5 min with gentle shaking. Thereafter, the cells were collected and washed with $800 \mu \mathrm{l}$ FBS to cease digestion. Finally, the cells were collected by centrifugation at $600 \times g$ for $6 \mathrm{~min}$ at $4{ }^{\circ} \mathrm{C}$ and used for immunoblotting analysis. For spermatocytes, after filtration through $40 \mu \mathrm{m}$ Nylon Cell Strainer, the digested cells were separated by their different sedimentation velocities at unit gravity at $4{ }^{\circ} \mathrm{C}$, using $2-4 \%$ bovine serum 
Fig. 1 PP6 is essential for male fertility. a Schematic diagram of deletion of Ppp6c exons and creation of Ppp6c $\Delta$ allele by Stra8-Cre-mediated recombination in male germ cells. b Western blotting analysis of PPP6C protein in $P p p 6 c^{W T}$ and $P p p 6 c^{c K O}$

spermatocytes of 8 -week-old mice. $\beta$-actin was detected as an internal control. c Pregnancy rates $(\%)$ of plugged wild-type females after mating with Ppp6c ${ }^{c K O}$ or Ppp6c ${ }^{W T}$ 8-weekold males. d Average litter size of plugged wild-type females after mating with $P p p 6 c^{c K O}$ or $P p p 6 c^{W T}$ 8-week-old males. For this part, at least five mice (8week-old) of each genotype were used for analysis. Data are presented as the mean \pm SEM. $P<0.05\left(^{*}\right), 0.01\left(^{* *}\right)$, or 0.001 $(* * *)$.
A
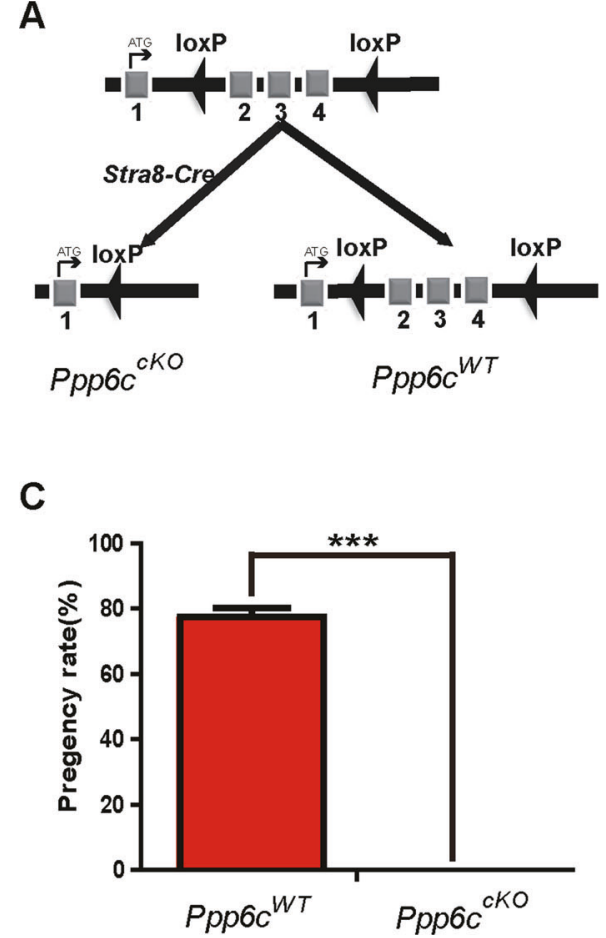

B

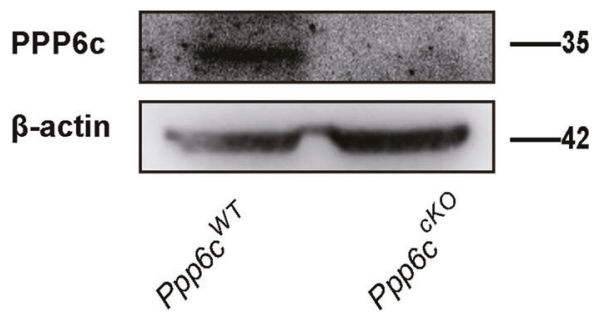

D

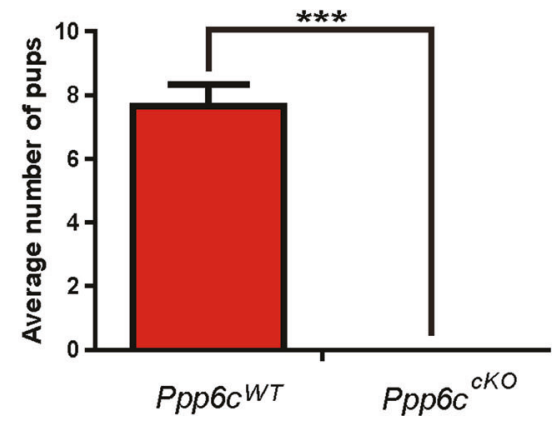

albumin gradient in Dulbecco's Modified Eagle Medium. Finally, we could collect adequate spermatocytes.

\section{Plasmid construction and immunoprecipitation (IP)}

Mouse Ppp6c gene (NM_024209.3) was cloned into pCS2 ${ }^{+}$ vector and mouse Takl gene (NM_009316.1) was cloned into pCMV vector. The plasmids were transfected into 293 T cells using lipofectamine 2000 (11668-019, Invitrogen) according to the reagent protocol. After $36 \mathrm{~h}$, the cells were washed by PBS and then were lysed in buffer for western and IP (P0013, Beyotime) supplemented with protease and phosphatase inhibitors (04693159001 and 04906845001; Roche). Next, the lysis buffer with cells were incubated on ice for $20 \mathrm{~min}$ and were centrifuged at $12,000 \mathrm{rpm}$ for $15 \mathrm{~min}$ at $4{ }^{\circ} \mathrm{C}$. The supernatant was collected into a new $1.5 \mathrm{ml}$ Eppendorf tube. For IP, $5 \%$ of the lysates served as input and the rest were incubated with $1 \mu \mathrm{l}$ HA-Tag antibody and $30 \mu \mathrm{l}$ Protein A/G Magentic beads (B23201, bimake) at $4{ }^{\circ} \mathrm{C}$ for $6 \mathrm{~h}$. Finally, these samples were diluted with an SDS loading buffer, heated at $95{ }^{\circ} \mathrm{C}$ for protein denaturalization, and then analyzed by western blotting.

\section{Statistical analysis}

All experiments were performed at least three times. Paired two-tailed Student's $t$ test was used for statistical analysis. Data were presented as mean \pm SEM and $P<$
$0.05(*), 0.01(* *)$, or $0.001(* * *)$ was considered statistically significant.

\section{Results}

\section{Germ cell-specific deletion of Ppp6c gene causes male infertility}

To investigate the function of PP6 in spermatogenesis (referred to as $P p p 6 c^{c K O}$ ), we first searched gene information about Ppp6c (NM_024209.3) and found that START codon was located in exon I. So, we generated $P p p 6 c^{F / F}$ mice in which exons II-IV of the Ppp6c gene were flanked with Loxp sites [28]. Then, PPP6c was specifically deleted from male germ cells by crossing $P p p 6 c^{F / F}$ mice with Stra 8 Cre transgenic mice (Fig. 1a). Stra8-Cre recombinase is specifically active in early-stage spermatogonia starting at 3 days after birth [33]. The results of western blotting (Fig. 1b) showed that PP6c was absent in spermatocytes of $P p p 6 c^{c K O}$ mice. Thus, we successfully established male germ cell-specific knockout mice for PP6.

The breeding assays showed that the Ppp6c $c^{c K O}$ male mice were completely infertile (Fig. 1c, d). Although copulatory plugs were routinely observed, no pups were obtained when adult $P p p 6 c^{c K O}$ males mated with normal fertile females. Compared with controls, the testes of ${ }_{P p p 6 c}{ }^{c K O}$ mice were much smaller (Fig. 2a) and the testis weight to body weight ratio of $P p p 6 c^{c K O}$ was significantly 
Fig. 2 PPP6c is required for spermatogenesis. a The testes of $P p p 6 c^{c K O}$ were smaller than those of the $P p p 6 c^{W T}$ (8-weekold, the same as below). b Testis weight to body weight ratio of $P p p 6 c^{W T}$ and Ppp6c ${ }^{c K O}$ mice $(n=7)$. Data are presented as the mean \pm SEM. $P<0.05(*)$, $0.01(* *)$, or $0.001(* * *)$. c Histological analysis of the caudal epididymides of the $P p p 6 c^{W T}$ and Ppp6c $c^{c K O}$ mice. (Scale bar: $50 \mu \mathrm{m}$ ) d

Histological analysis of the seminiferous tubules of the $P p p 6 c^{W T}$ and $P p p 6 c^{c K O}$ mice. Scale bar: (top) $100 \mu \mathrm{m}$; (bottom) $50 \mu \mathrm{m}$
A

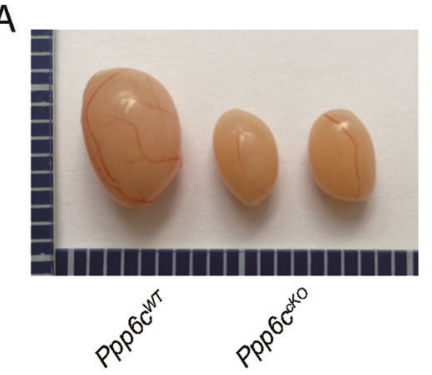

B

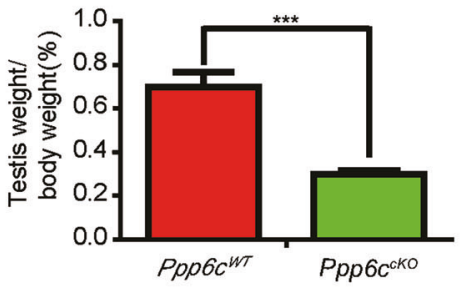

C

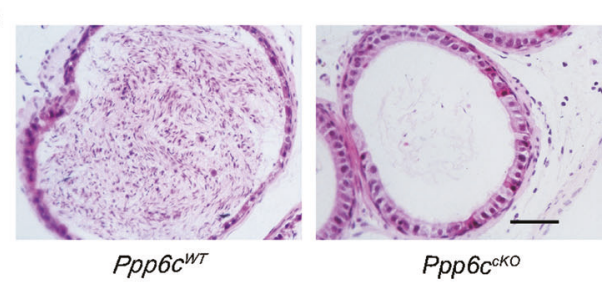

D

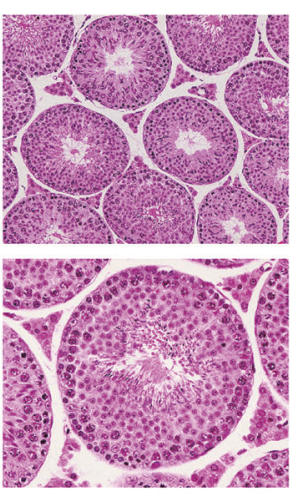

Ppp6c WT

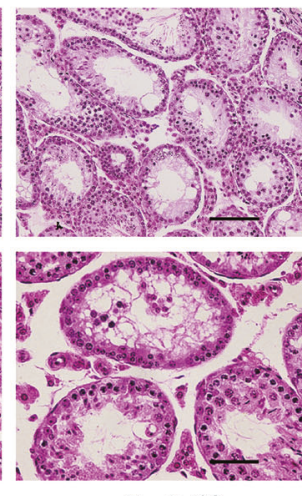

Ppp6c cko lower (Fig. 2b). We next analyzed the histology of the epididymides and testes by hematoxylin and eosin (H\&E) staining. The results showed that almost no mature spermatozoa were found in the epididymal lumens of $P p p 6 c^{c K O}$ mice (Fig. 2c). The seminiferous tubules of $P p p 6 c^{W T}$ testes contained a basal population of spermatogonia, several types of spermatocytes and spermatids. However, germ cells were severely reduced in number, and nearly no round or elongated spermatids were observed in the testes of Ppp $6 c^{c K O}$ males (Fig. 2d, Fig. S1A, and Fig. S1B). These results demonstrate that germ cell-specific PPP6c knockout results in spermatogenesis failure and thus male infertility.

\section{The PPP6c-deficient spermatocytes arrest at the pachytene stage}

To identify exactly which stage of spermatogenesis was affected in PPP6c-deficient mice, we performed H\&E and immunofluorescence staining of the germ cell marker MVH to characterize the first wave of spermatogenesis in mice at 9 dpp (days postpartum), when testes begin to generate leptotene spermatocytes, at $12 \mathrm{dpp}$, when testes begin to generate zygotene spermatocytes, and at $14 \mathrm{dpp}$, when testes begin to generate pachytene spermatocytes. The results revealed that the numbers of germ cells of $P p p 6 c^{c K O}$ mice were similar to $P p p 6 c^{W T}$ mice at $9 \mathrm{dpp}$, but these numbers decreased sharply at $12 \mathrm{dpp}$ and $14 \mathrm{dpp}$ (Fig. 3a, b and Fig S2A), suggesting that the prophase of meiosis I was affected in Ppp6c ${ }^{c K O}$ mice. Spermatogenesis can be subdivided into 12 stages in mouse testes using PAS and hematoxylin staining of sections [34]. To identify which stages of spermatogenesis were affected after PPP6c deletion, sections were stained with PAS and hematoxylin and we discovered that spermatogenesis of PPP6c-deficient mice was blocked at stages IV and most of the spermatocytes arrested at the pachytene stage (Fig. 3c). The percentage of germ cells was sharply decreased in Ppp $6 c^{c K O}$ mice from 12dpp (Fig. 3b), probably because the pachytene checkpoint-arrested spermatocytes were undergoing apoptosis. To test this possibility, TUNEL assay was performed, and the results showed that germ cells underwent apoptosis in the Ppp6c ${ }^{c K O}$ mice (Fig. 3d, Fig S2B, and Fig S2C).

Based on the above results, we found that PPP6Cdeficient spermatocytes were abnormal. Therefore, its localization was first analyzed by spermatocyte surface spreading. During meiosis I prophase, the localization of PPP6c was consistent during different stages. From leptotene to diakinesis, PPP6c was always localized to the nucleus. PPP6c aggregated strongly throughout the nucleus during the zygotene stage to the diplotene stage (Fig. 4a). Moreover, we identified various stages of meiotic prophase I by staining for a component of the synaptonemal complex, SYCP3 [35]. All meiotic prophase I stages could be found in the spermatocyte nuclei of $P p p 6 c^{W T}$ testes, whereas only spermatocytes from the leptotene to the pachytene stages were observed in the Ppp6c ${ }^{c K O}$ mice testes (Fig. 4b). Further quantification of the meiotic prophase I stages in testes showed that the proportion of the early-pachytene cells was increased and that of mid-pachytene cells, diplotene cells and diakinesis cells was significantly decreased in the Ppp6c ${ }^{c K O}$ mice (Fig. 4c). All these results indicate that the depletion of PPP6c leads to a pachytene stage arrest and thus spermatocyte death. 
A

9dpp
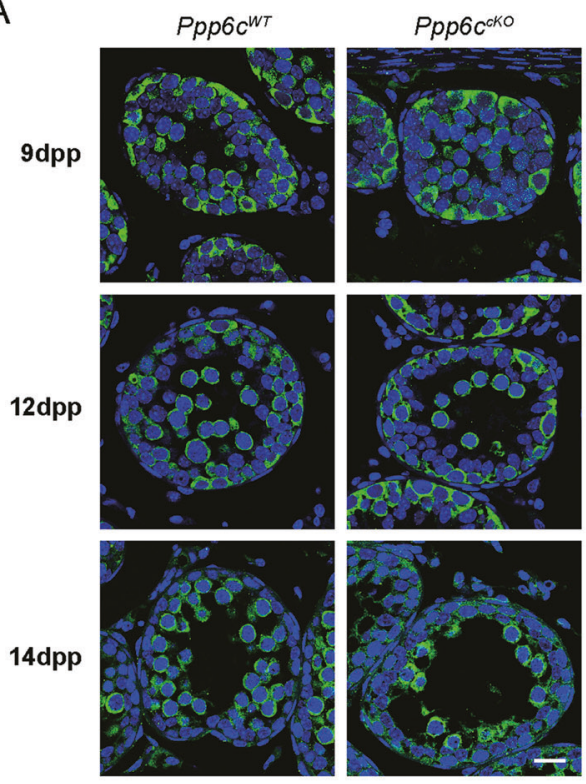

B

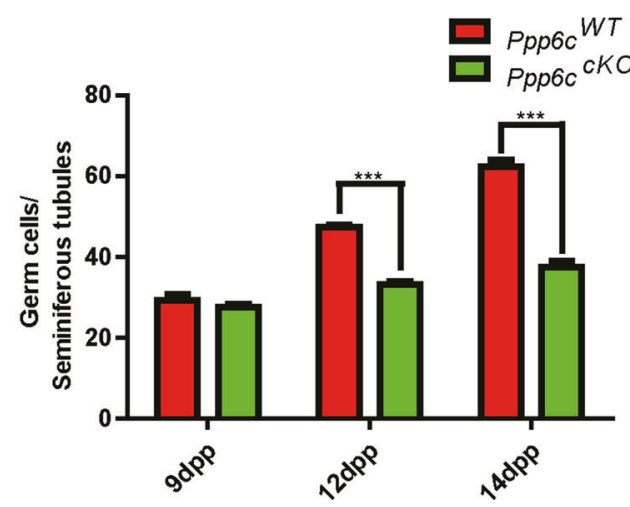

Fig. 3 PPP6c depletion results in the abnormality and apoptotic death of spermatocytes. a MVH immunofluorescence analysis of the juvenile $P p p 6 c^{W T}$ and $P p p 6 c^{c K O}$ mice showed that the amount of the germ cells began to drop from $12 \mathrm{dpp}$ to $14 \mathrm{dpp}$. (Scale bar: $20 \mu \mathrm{m}$ ) b Quantification of the germ cells in the seminiferous tubules of the juvenile $P p p 6 c^{W T}$ and $P p p 6 c^{c K O}$ mice. For each time point, at least three mice of each genotype were used for analysis. Data are presented as the mean \pm SEM. $P<0.05(*), 0.01(* *)$, or $0.001(* * *)$.

\section{PPP6c depletion causes unsuccessfully programmed DSB repair}

According to the above-presented data, $P p p 6 c^{c K O}$ mice displayed defects in the pachytene stage. Programmed DSB repair mainly occurs at this stage. Chromosome synapsis and recombination are facilitated by the introduction of DSB [36], which can be monitored by detecting $\gamma \mathrm{H} 2 \mathrm{AX}-$ positive foci at the leptotene and zygotene stages and these are decreased on autosomes after DSB repair at the pachytene stage [37]. In the $P p p 6 c^{c K O}$ spermatocytes, the $\gamma \mathrm{H} 2 \mathrm{AX}$ signal was detected at the leptotene and zygotene
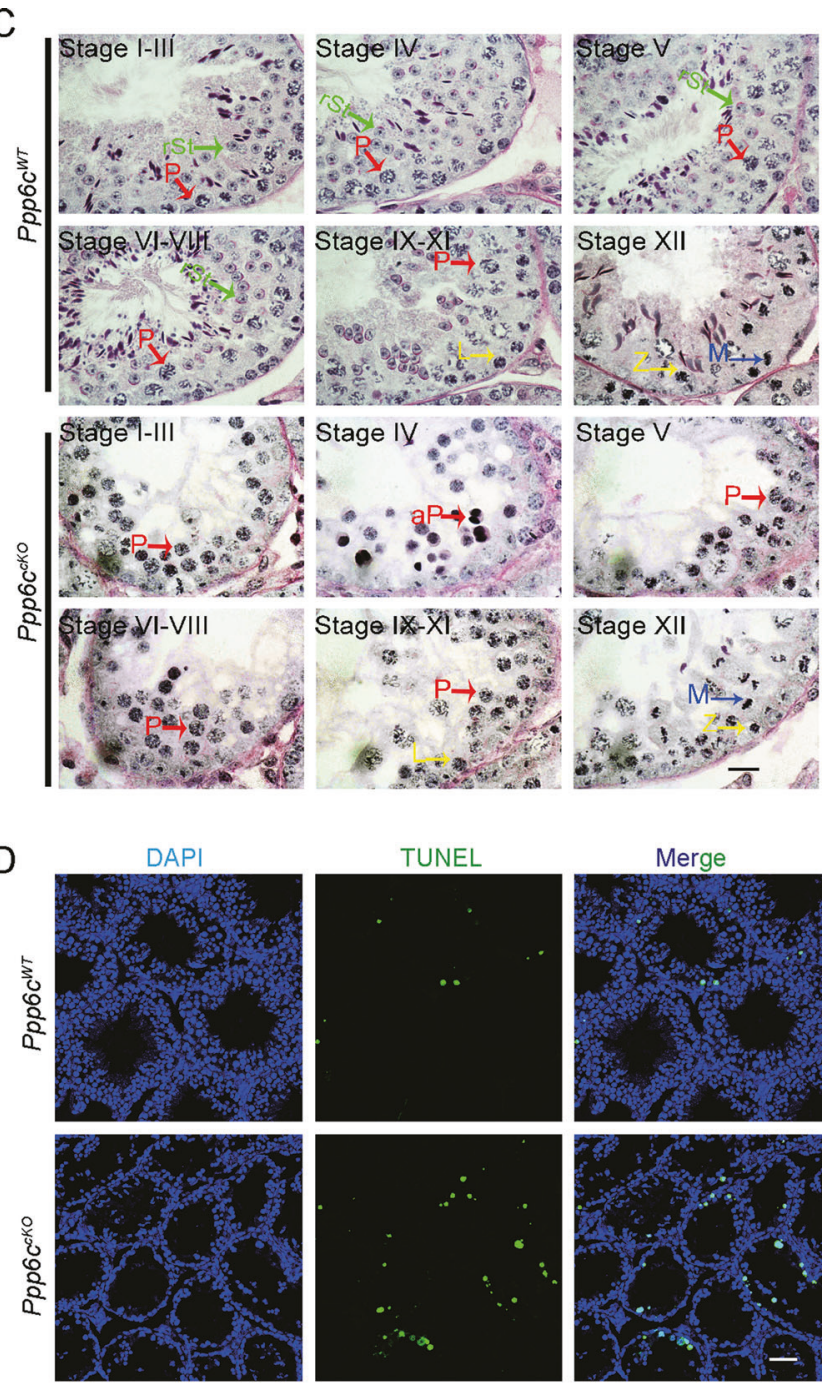

c Seminiferous tubules paraffin sections from $P p p 6 c^{W T}$ and $P p p 6 c^{c K O}$ testis (8-week-old) were stained with PAS-hematoxylin. L leptotene spermatocytes, Z zygotene spermatocytes, $\mathrm{P}$ pachytene spermatocytes, $\mathrm{aP}$ apoptotic pachytene spermatocytes, $\mathrm{M}$ meiotic divisions, $\mathrm{rSt}$ round spermatids. (Scale bar: $20 \mu \mathrm{m})$ d TUNEL immunofluorescence staining of the testes of Ppp6c $c^{W T}$ and Ppp $6 c^{c K O}$. (Scale bar: $50 \mu \mathrm{m}$ ) Green: TUNEL positive signal; Blue: DAPI. At least three mice ( 8 -week-old) of each genotype were used for analysis.

stages, which was similar to Ppp6c ${ }^{W T}$ spermatocytes, indicating normal production of DSB (Fig. 5a). However, in the Ppp $6 c^{c K O}$ spermatocytes, the $\gamma \mathrm{H} 2 \mathrm{AX}$ signal was still diffused on the autosomes at the pachytene stage, rather than being accumulated only on the XY bodies (Figs. 5a, b). Consistent with the $\gamma \mathrm{H} 2 \mathrm{AX}$ staining, pATM, which is integral to the regulation of programmed DSB formation [38], was also detected on the autosomes of $P p p 6 c^{c K O}$ spermatocytes (Fig. 5c). These results suggested that PPP6c might be involved in programmed DSB formation and repair. PPP6c depletion caused failure in programmed DSB repair. 
A
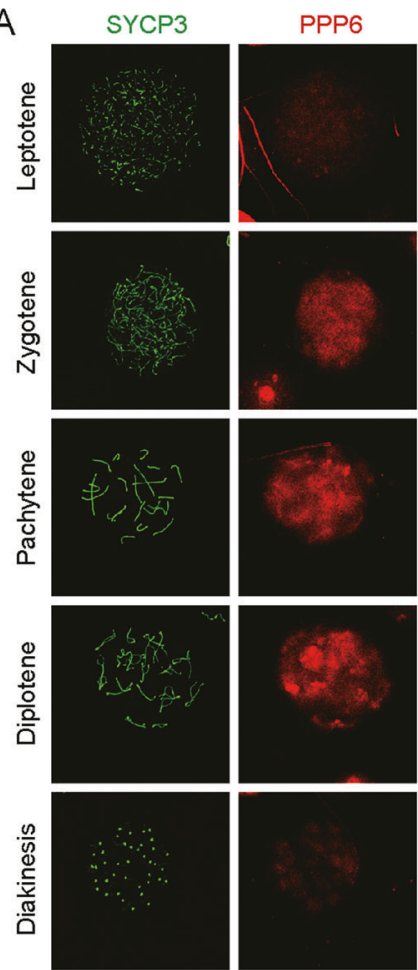

C

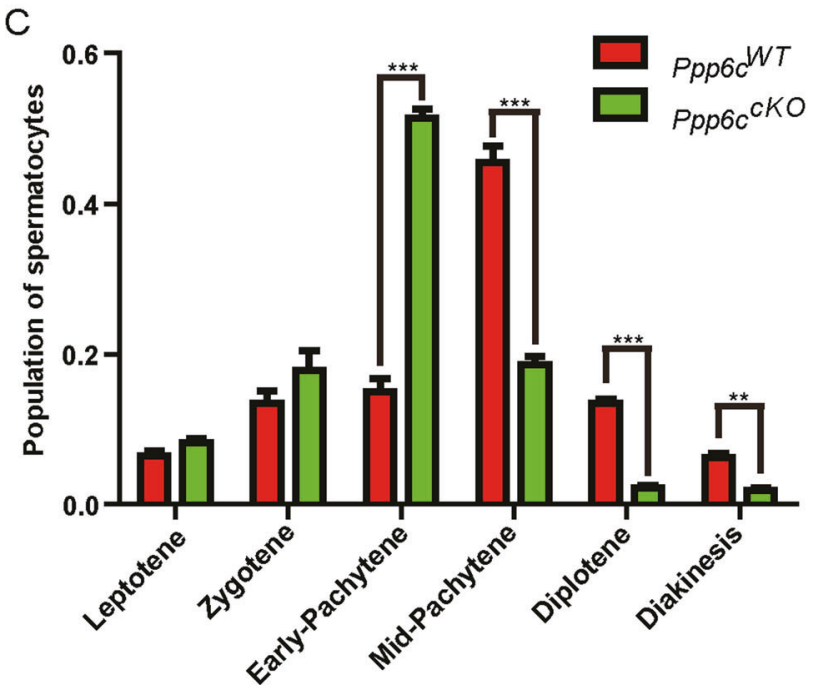

B

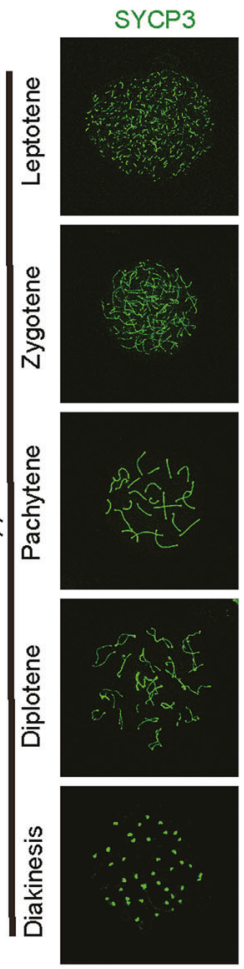

SYCP3

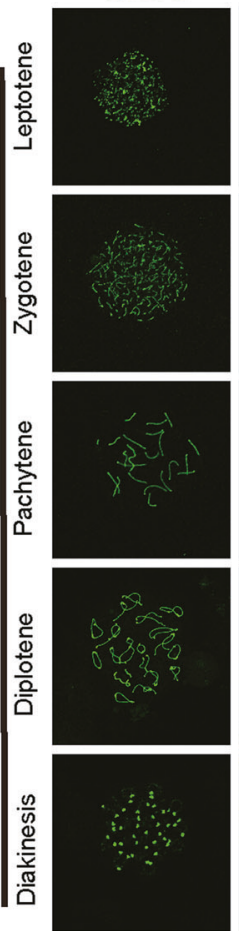

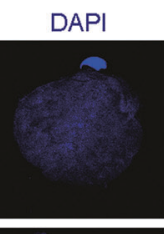
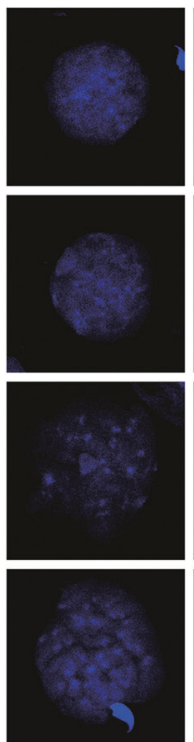

DAPI
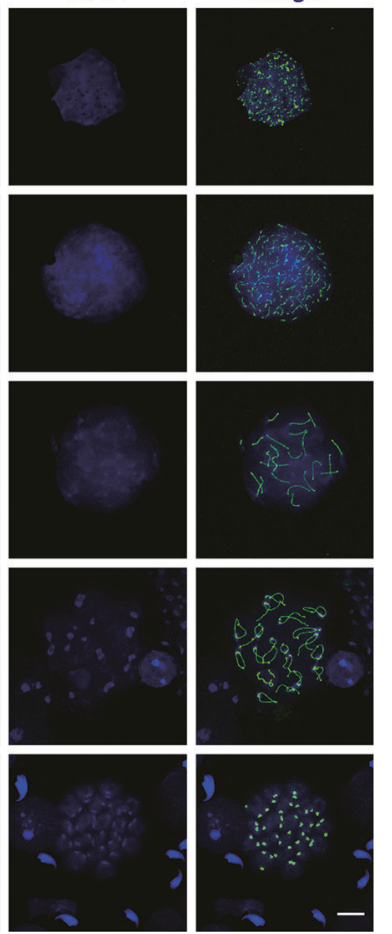

Fig. 4 PPP6c-deficient spermatocytes arrest at pachytene stage. a Representative images of subcellular localization of PPP6c during spermatogenesis. Spermatocytes (8-week-old) were double stained for PPP6c (red) and SYCP3 (green) at leptotene, zygotene, pachytene, diplotene, and diakinesis stages. (Scale bar: $10 \mu \mathrm{m})$. b Spermatocyte stages in prophase in $P p p 6 c^{W T}$ and $P p p 6 c^{c K O}$ spermatocytes (8-week- old). Chromosome spreads of spermatocytes were immunostained with antibodies against SYCP3 (green) and DAPI stain (blue). Scale bar: $10 \mu \mathrm{m}$. (Meiotic stage frequencies in Ppp6c $c^{W T}$ and Ppp6c ${ }^{c K O}$ testes. For this part, at least three mice (8-week-old) of each genotype were used for analysis. Data are presented as the mean \pm SEM. $P<0.05(*)$, $0.01(* *)$, or $0.001(* * *)$. 
Fig. 5 Programmed DSBs are not repaired efficiently due to PPP6c depletion. a $P p p 6 c^{W T}$ and $P$ Pp $6 c^{c K O}$ chromosome spreads of spermatocytes were immunostained with antibodies against SYCP3 (green) and $\gamma \mathrm{H} 2 \mathrm{AX}$ (red). $\gamma \mathrm{H} 2 \mathrm{AX}$ marked DSB in spermatocytes (8-weekold). Scale bar: $10 \mu \mathrm{m}$. b Percentage of cells retaining H2AX outside the sex chromosomes in Ppp6c ${ }^{W T}$ and Ppp $6 c^{c K O}$ pachytene

spermatocytes $(n=3 ; 300$ cells $)$. c Ppp6c $c^{W T}$ and Ppp6c $c^{c K O}$ chromosome spreads of spermatocytes (8-week-old) were immunostained with antibodies against SYCP3 (red) and pATM (green). Scale bar: $10 \mu \mathrm{m}$.
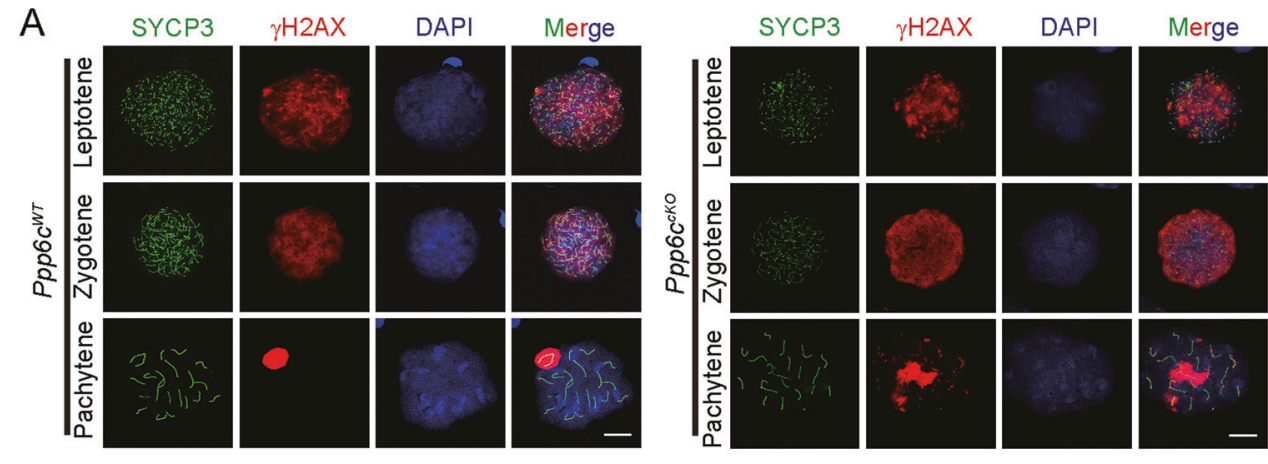

B

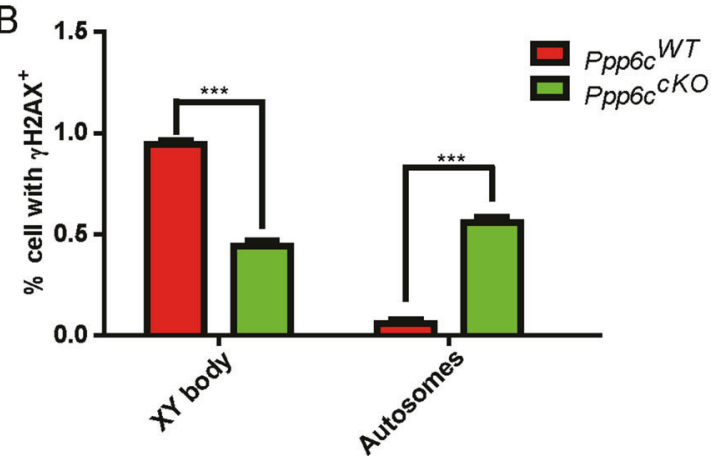

\section{PPP6c deletion results in impaired meiotic recombination in spermatocytes}

In general, defects in meiotic recombination are significant causes for pachytene stage arrest [39]. Meiotic recombination is dependent on the successful repair of programmed DSB. We examined proteins involved in meiosis-specific programmed DSB formation and recombination, such as SYCP1, MRE11, DMC1, and MLH1. SYCP1 is one of the important components of the synaptonemal complexs and it is the central element that links two homologous chromosomes for pairing [35]. The MRN complex, consisting of MRE11, RAD50, and NBS1, is involved in DSB end resectioning [40]. RAD51 and DMC1 are important marker molecules for different stages of meiotic recombination. BRCA1 associates with RAD51 and RAD51/DMC1 facilitate the invasion of homologous chromosomes [41, 42]. MLH1 represents crossovers during meiotic recombination [43]. First, we examined chromosomal synapsis by using SYCP1 antibody staining and found that SYCP1 signals of $P p p 6 c^{c K O}$ mice were similar to those of Ppp6c ${ }^{W T}$ mice (Fig S3C). By western blotting, we found that MRE11 decreased dramatically in $P p p 6 c^{c K O}$ spermatocytes (Fig. 6e), suggesting that the MRN complex might be insufficiently recruited to the programmed DSB sites in $P p p 6 c^{c K O}$ mice. The number of DMC1 foci in $P p p 6 c^{c K O}$ spermatocytes was also decreased compared with that of the Ppp $6 c^{W T}$ mice (Fig. 6a, b). Moreover, we performed immunoblotting using germ cell lysates from $P p p 6 c^{W T}$ and $P p p 6 c^{c K O}$ mice. As shown in Fig. 6e, the levels of DMC1 were all significantly decreased in Ppp6c ${ }^{c K O}$ mice, suggesting defects in single strand DNA invasion or generation. We also found that the number of MLH1 foci of Ppp6c $c^{c K O}$ mice was significantly reduced compared with that of $P p p 6 c^{W T}$ mice (Fig. 6c, d), suggesting the crossover formation was also impaired. All these results suggested that PPP6c deletion might influence recombination and crossover formation, finally resulting in a pachytene stage arrest.

\section{PPP6c promotes chromatin relaxation to regulate meiotic recombination}

To investigate the mechanism underlying PPP6c deletioncaused pachytene stage arrest, we found that chromatin relaxation seems to be critical for meiotic recombination initiation and repair [44]. We proposed that PP6 might influence meiotic recombination by affecting chromatin structure. To test this possibility, we examined the acetylation status of $\mathrm{H} 3 \mathrm{~K} 14$ (H3K14ac), which is an active transcription histone marker, and dimethylation at histone H3K9 (H3K9me2), which is a heterochromatin-associated modification marker [45-47]. By spermatocyte surface spreading and western blotting, we found the level of H3K9me2 was significantly increased in $P p p 6 c^{c K O}$ mice, whereas the level of H3K14ac was sharply decreased in Ppp6c ${ }^{c K O}$ mice (Fig. 7a, b, and Fig S4), suggesting that PPP6c-deficient spermatocytes could not normally promote chromatin relaxation. Based on the above results, PPP6c depletion phenotypes could be explained by which PPP6c mediates chromatin structures and allows the 
A

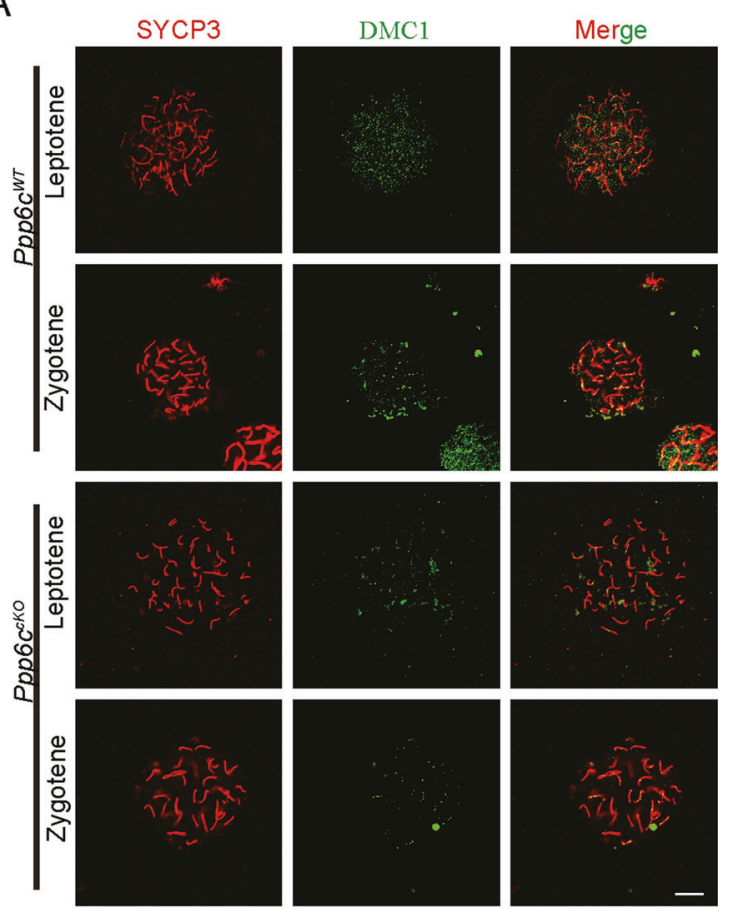

B

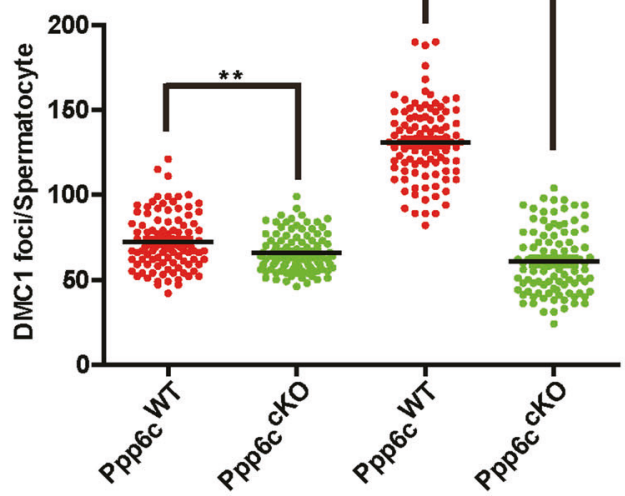

Fig. 6 Strand invasion, meiotic crossover, and recombination are impaired in Ppp6c ${ }^{c K O}$ spermatocytes. a Spermatocytes stained for SYCP3 (red) and DMC1 (green) in Ppp6 $c^{W T}$ and Ppp6c $c^{c K O}$ 8-week-old mice. Scale bar: $10 \mu \mathrm{m}$. b Quantification of DMC1 foci in leptotene stage and zygotene stage $(n=3 ; 100$ cells). c Spermatocytes stained for SYCP3 (red) and MLH1 (green) in Ppp6c ${ }^{W T}$ and $P p p 6 c^{c K O} 8$ week-old mice. MLH1 is a recombination marker in $P p p 6 c^{W T}$

recruitment of DSB repair factors to the proper position during meiosis.

However, how does the PPP6c mediate chromatin structures? It has reported that the mitogen-activated protein kinase (MAPK) pathway is required for maintaining the chromatin condensation during G2/M progression, whereas chromatin is relaxed in pachytene stage [48]. TAK1 (transforming growth factor-activated kinase 1) is a member of the mitogen-activated protein kinase kinase kinase (MAPKKK) family [49]. Moreover, ERK, as TAK1
C

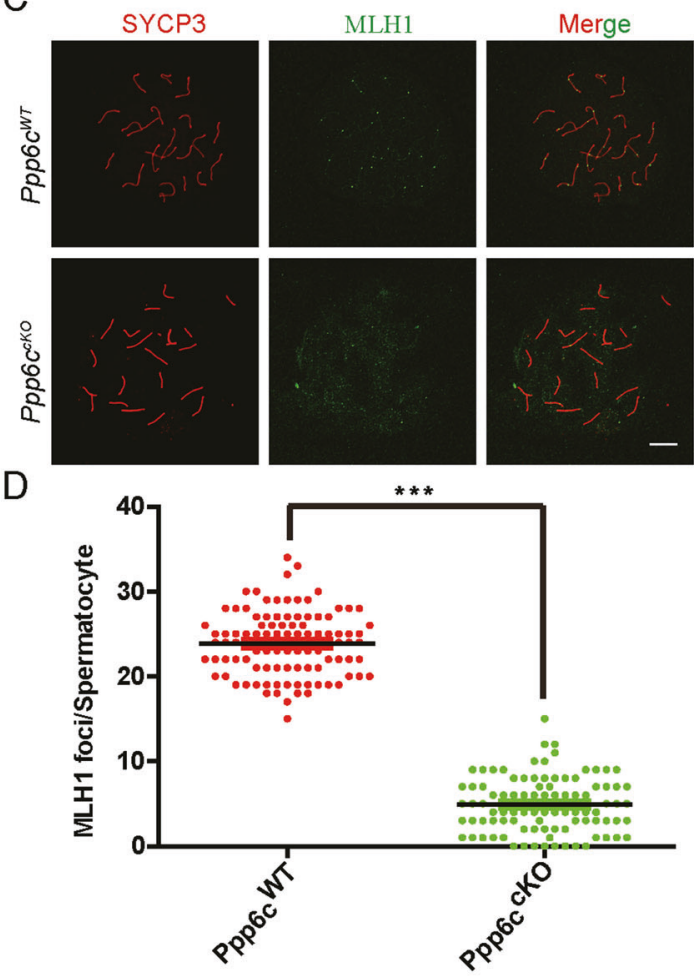

E
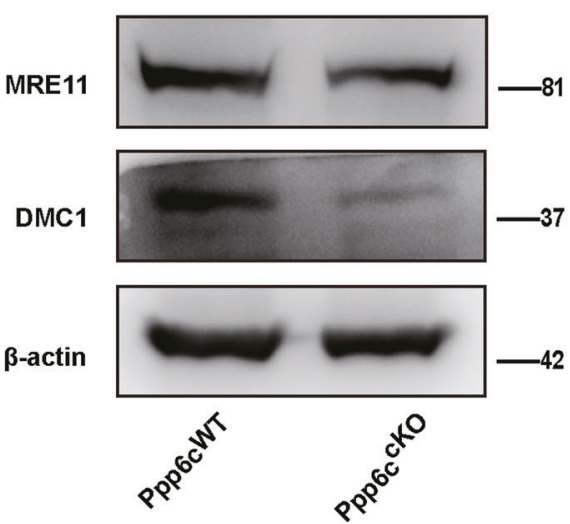

spermatocytes and decreased MLH1 staining was observed in $P$ Pp $6 c^{c K O}$ mice spermatocytes Scale bar: $10 \mu \mathrm{m}$. d MLH1 signals were counted in spreads. Quantification of the MLH1 foci numbers per cell in the Ppp6c $c^{W T}$ and $P p p 6 c^{c K O}$ spermatocytes $(n=3 ; 100$ cells). e Immunoblotting analysis of MRE11, DMC1 in $P p p 6 c^{W T}$, and $P p p 6 c^{c K O}$ germ cells (12 dpp). Level of $\beta$-actin was detected as internal control. Each experiment was repeated at least three times.

downstream kinases, is a member of mitogen-activated protein kinase (MAPK) [50]. Upon activation of the MAPK pathway, p90Rsk2 interacts with and phosphorylates Nek2, which is bound to DNA through interaction with HMGA2. Phosphorylation of HMGA2 by Nek2 decreases its affinity for DNA and favors its release from the chromatin, possibly permitting condensation factors to enter the chromatin and to trigger chromosome condensation $[48,51]$. Therefore, we proposed that there may have an interaction between PPP6c and TAK1. PPP6c may mediate chromatin structures 
A

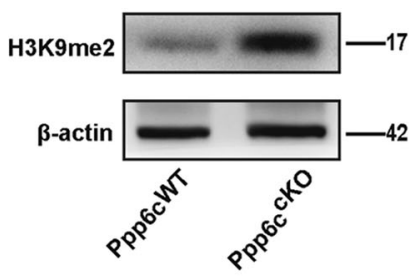

C

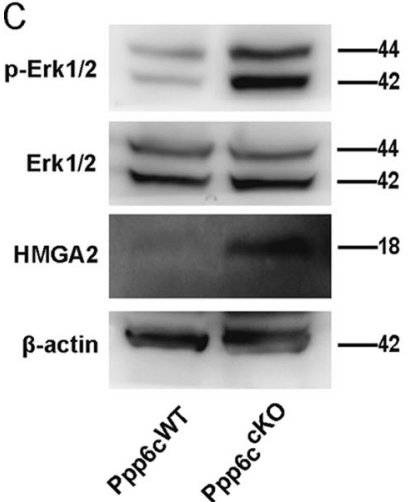

Fig. 7 PP6 promotes chromatin relaxation to regulate meiotic recombination dependent on MAPK pathway activity. a Immunoblotting detection of the expression of $\mathrm{H} 3 \mathrm{~K} 9 \mathrm{me} 2$ in spermatocytes of Ppp6c $c^{W T}$ and $P p p 6 c^{c K O}$ mice ( 8 week). b Immunoblotting detection of the expression of $\mathrm{H} 3 \mathrm{~K} 14 \mathrm{ac}$ in spermatocytes of $P p p 6 c^{W T}$ and $P p p 6 c^{c K O}$ mice ( 8 week). c Immunoblotting detection of the expression of p-ERK1/2, ERK1/2, and HMGA2 in spermatocytes of $P p p 6 c^{W T}$ and
B

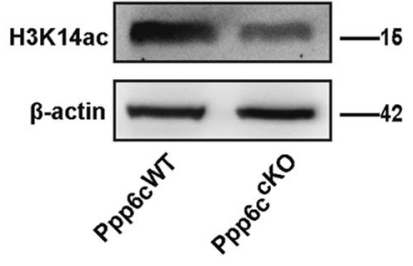

E
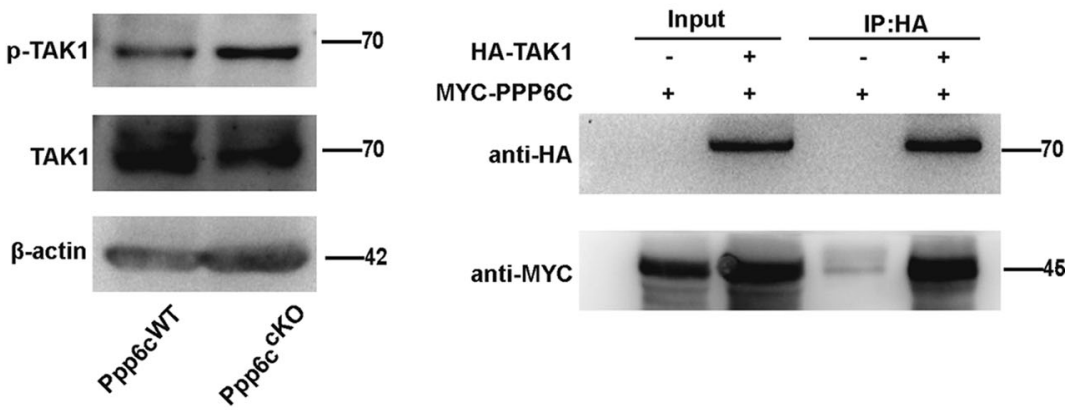

$P p p 6 c^{c K O}$ mice (8 week). d Immunoblotting detection of the expression of p-TAK1 and TAK1 in spermatocytes of Ppp6c ${ }^{W T}$ and Ppp6c ${ }^{\text {cKO }}$ mice ( 8 week). e 293 cells were transfected with expression vectors for HA-Tak1 and MYC-PPP6c. The negative controls were transfected with expression vectors for HA and MYC-PPP6c. Proteins from the cell lysates were immunoprecipitated with anti-HA, and immunoblotted with anti-MYC and anti-HA. IP, immunoprecipitation.

dependent on MAPK pathway activity. To test this possibility, we first performed immunoblotting using spermatocytes from $P p p 6 c^{W T}$ mice and $P p p 6 c^{c K O}$ mice to detect relevant phosphorylated protein levels of MAPK pathway. As expected, the level of p-ERK1/2 and p-TAK1 protein was markedly increased in $P p p 6 c^{c K O}$ mice (Fig. 7c, d), suggesting that the absence of PPP $6 c$ affected MAPK pathway activity. Meanwhile, we found that the level of HMGA2 was increased (Fig. 7c), indicating that it was released from the chromatin, finally resulting in chromatin condensation. Moreover, the myc-PPP6c and HA-TAK1 were expressed in $293 \mathrm{~T}$ cells for IP experiments. As expected, PPP6c clearly immunoprecipitated with TAK1 (Fig. 7e). Therefore, we confirm that PPP6c interacts with TAK1 and deletion of PPP $6 c$ results in premature chromatin condensation.

\section{Discussion}

As a member of the PP2A-like subfamily, PP6 is well known for its functional role in mitosis [26, 52]. Our recent study also revealed a critical role for PP6 in oocyte development $[28,29]$. In this study, by crossing $P p p 6 c^{F / F}$ mice with Stra8-Cre mice to generate mutant mice with a specific deletion of Ppp6c in male germ cells, we were able to investigate the potential roles of PP6 in male germ cell meiosis and spermatogenesis. We found that PP6 is required for meiosis and fertility in males. Of particular note, in $P p p 6 c^{c K O}$ mice, the spermatocytes arrested at the pachytene stage and programmed DSB repair failed.

Meiosis is a specific process for gamete formation in sexually reproducing organisms, which is generally considered to be the most crucial phase of spermatogenesis. Correct execution of meiosis is essential for fertility, for maintaining the integrity of the genome and for ensuring normal development of the offspring [53]. Meiotic prophase I is subdivided into four cytological stages: leptotene (chromatin condensation, initiation of DSB, and meiotic recombination), zygotene (initiation of synapsis of homologous chromosomes), pachytene (full synapsis, development of recombination sites into at least one crossover per homologous chromosome pair), and diplotene (de-synapsis and visible crossover sites, the so-called chiasmata) [54]. A specific event of this process is meiotic recombination between paternal and maternal chromosomes. Meiotic recombination involves several steps including formation of DSB, DSB end resection, and strand invasion into a chromatid of the homologous chromosome [55]. During meiotic recombination, there are specifically related proteins, such 


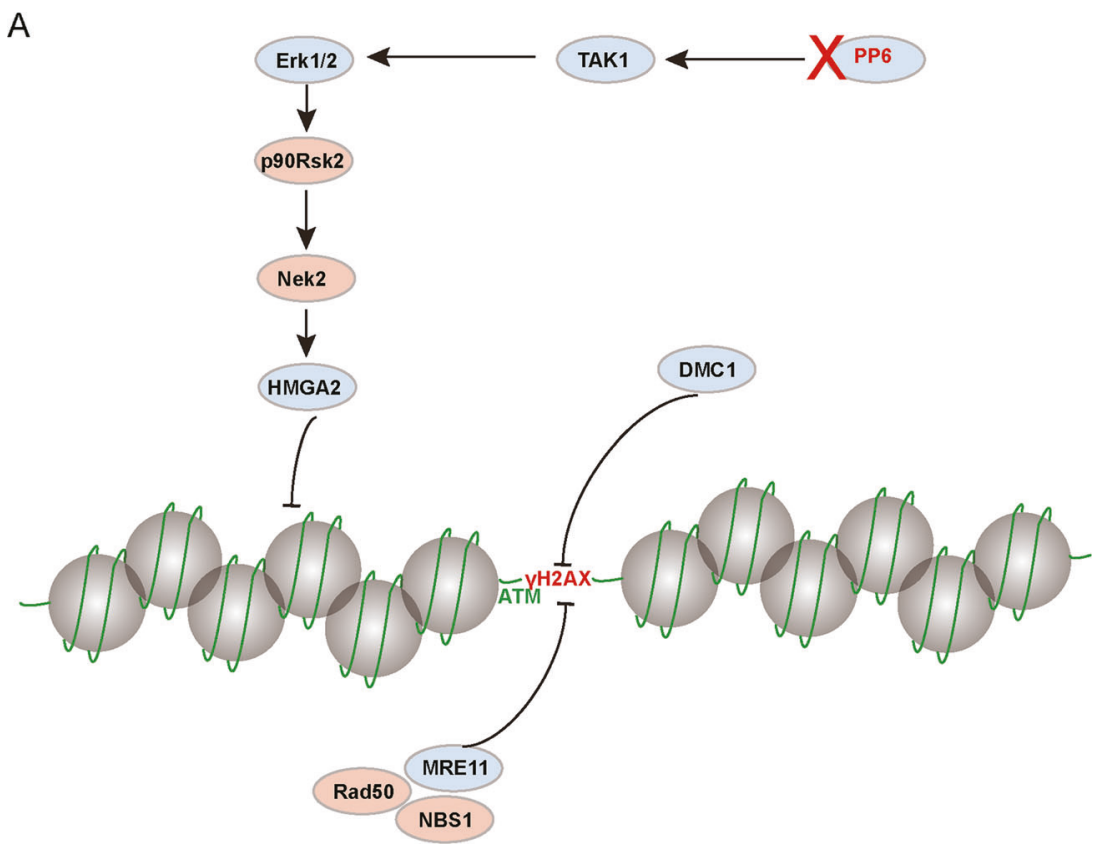

Fig. 8 A hypothetical model of the function of PP6 during meiotic recombination. a In the $P p p 6 c^{c K O}$ spermatocytes, TAK 1 cannot be normally dephosphorylated, resulting in persistent MAPK pathway activation. Upon activation of the MAPK pathway, p90Rsk2 interacts with and phosphorylates Nek2, which is bound to DNA through interaction with HMGA2. Phosphorylation of HMGA2 by Nek2 decreases its affinity for DNA and favors its release from the

as SPO11, MRN complex, BRCA1, DMC1, RAD51, MLH1. In our study, we found that these related proteins decreased dramatically in Ppp6c ${ }^{c K O}$ spermatocytes (Fig. 6). We speculated that the decreasing presence of these proteins is likely owing to failed recruitment to the programmed DSB sites. Finally, PPP6c depletion causes failure of programmed DSBs repair.

Several components of the chromatin remodeling protein, such as switching defective/sucrose non-fermenting (SWI/ SNF) and RNF20, might be involved in chromatin relaxation during meiotic recombination $[46,56]$. In our study, male germ cells-specific knockout of PPP6c resulted in a dramatic increase in MAPK pathway activity (Fig. 7). Upon activation of the MAPK pathway, p90Rsk2 interacts with and phosphorylates Nek2, which is bound to DNA through interaction with HMGA2. Phosphorylation of HMGA2 by Nek2 decreases its affinity for DNA and favors its release from the chromatin, permitting condensation factors to enter the chromatin and to trigger chromosome condensation [48]. Consequently, the MRN complex and other recombination protein factors could not be efficiently recruited to the programmed DSB sites, and those DSBs could not be repaired by meiotic recombination, resulting in spermatocyte cell apotosis and finally male infertility in mice (Fig. 8). Infertility affects $10-15 \%$ couples in their reproductive life, and $\sim 20-30 \%$ of infertility is caused by male factors [57]. In chromatin, possibly permitting condensation factors to enter the chromatin and to trigger chromosome condensation. As such, meiotic chromatin cannot be relaxed, which affects the efficient recruitment of the MRN complex (MRE11/RAD50/NBS1) and other DNA repair factors to the DSB sites. Therefore, programmed DSBs cannot be repaired by meiotic recombination, resulting in spermatocyte cell apoptosis and finally male infertility in mice.

humans, male infertility such as azoospermia or severe oligozoospermia is mostly characterized by decreased semen parameters [58]. Azoospermia or severe oligozoospermia is a multifactorial disorder caused by genetic, epigenetic, and environmental factors [59]. The majority $(\sim 75 \%)$ of male patients with spermatogenic failure are idiopathic, and a genetic factor is often considered to be one of the major causes [60, 61]. The PPP6c-deficient mouse model produces a phenotype that is very similar to some cases of human azoospermia or oligozoospermia. Although there are no reported PP6-associated male infertility patients, the existence of these types of patients should not be discounted. Many cases of male infertility remain undetermined. In summary, our study demonstrated for the first time that PP6 regulates meiotic recombination by promoting chromatin relaxation and facilitating the recruitment of some meiotic recombination-related factors to the chromatin through the MAPK pathway.

Acknowledgements We appreciate and acknowledge Shiwen $\mathrm{Li}$ and Xili Zhu for their technical assistance. We thank all members of the Sun laboratories for their help and discussion. We thank Drs Xingzhi $\mathrm{Xu}$ and Xiao Yang for providing the $P p p 6 c^{F / F}$ mice. We thank Xiaoqing Nie for the culture of 293T-cells. This study was supported by the National R\&D Program of China (2018YFA0107701, 2016YFC1000600), NSFC $(31530049,31701299)$ and the Youth Innovation Promotion Association (CAS 2017114). 


\section{Compliance with ethical standards}

Conflict of interest The authors declare that they have no conflict of interest.

Publisher's note Springer Nature remains neutral with regard to jurisdictional claims in published maps and institutional affiliations.

\section{References}

1. Oatley JM, Brinster RL. Regulation of spermatogonial stem cell self-renewal in mammals. Annu Rev Cell Dev Biol. 2008;24:263-86

2. Moens PB. Molecular perspectives of chromosome pairing at meiosis. BioEssays. 1994;16:101-6.

3. de Vries SS, Baart EB, Dekker M, Siezen A, de Rooij DG, de Boer P, et al. Mouse MutS-like protein Msh5 is required for proper chromosome synapsis in male and female meiosis. Genes Dev. 1999;13:523-31.

4. Costa Y, Speed R, Ollinger R, Alsheimer M, Semple CA, Gautier $\mathrm{P}$, et al. Two novel proteins recruited by synaptonemal complex protein 1 (SYCP1) are at the centre of meiosis. J Cell Sci. 2005;118:2755-62.

5. Lange J, Pan J, Cole F, Thelen MP, Jasin M, Keeney S. ATM controls meiotic double-strand-break formation. Nature 2011;479:237-40.

6. Lange J, Yamada S, Tischfield SE, Pan J, Kim S, Zhu X, et al. The landscape of mouse meiotic double-strand break formation, processing, and repair. Cell 2016;167:695-708 e16.

7. Page SL, Hawley RS. Chromosome choreography: the meiotic ballet. Science. 2003;301:785-9.

8. Nagaoka SI, Hassold TJ, Hunt PA. Human aneuploidy: mechanisms and new insights into an age-old problem. Nat Rev Genet. 2012;13:493-504.

9. Inselman A, Handel MA. Mitogen-activated protein kinase dynamics during the meiotic G2/MI transition of mouse spermatocytes. Biol Reprod. 2004;71:570-8.

10. Bielinski VA, Mumby MC. Functional analysis of the PP2A subfamily of protein phosphatases in regulating Drosophila S6 kinase. Exp Cell Res. 2007;313:3117-26.

11. Cohen PT, Philp A, Vazquez-Martin C. Protein phosphatase 4from obscurity to vital functions. FEBS Lett 2005;579:3278-86.

12. Ruediger R, Ruiz J, Walter G. Human cancer-associated mutations in the Aalpha subunit of protein phosphatase 2A increase lung cancer incidence in Aalpha knock-in and knockout mice. Mol Cell Biol. 2011;31:3832-44.

13. Hu MW, Wang ZB, Jiang ZZ, Qi ST, Huang L, Liang QX, et al. Scaffold subunit Aalpha of PP2A is essential for female meiosis and fertility in mice. Biol Reprod. 2014;91:19.

14. Toyo-oka K, Mori D, Yano Y, Shiota M, Iwao H, Goto H, et al. Protein phosphatase 4 catalytic subunit regulates Cdk1 activity and microtubule organization via NDEL1 dephosphorylation. J Cell Biol. 2008;180:1133-47.

15. Zhang X, Ozawa Y, Lee H, Wen YD, Tan TH, Wadzinski BE, et al. Histone deacetylase 3 (HDAC3) activity is regulated by interaction with protein serine/threonine phosphatase 4. Genes Dev. 2005;19:827-39.

16. Yeh PY, Yeh KH, Chuang SE, Song YC, Cheng AL. Suppression of MEK/ERK signaling pathway enhances cisplatin-induced NFkappaB activation by protein phosphatase 4-mediated NF-kappaB p65 Thr dephosphorylation. J Biol Chem. 2004;279:26143-8.

17. Shaltiel IA, Aprelia M, Saurin AT, Chowdhury D, Kops GJ, Voest EE, et al. Distinct phosphatases antagonize the p53 response in different phases of the cell cycle. Proc Natl Acad Sci USA. 2014;111:7313-8

18. Krauthammer M, Kong Y, Ha BH, Evans P, Bacchiocchi A, McCusker JP, et al. Exome sequencing identifies recurrent somatic RAC1 mutations in melanoma. Nat Genet 2012;44:1006-14.

19. Hodis E, Watson IR, Kryukov GV, Arold ST, Imielinski M, Theurillat JP, et al. A landscape of driver mutations in melanoma. Cell. 2012;150:251-63.

20. Couzens AL, Knight JD, Kean MJ, Teo G, Weiss A, Dunham $\mathrm{WH}$, et al. Protein interaction network of the mammalian Hippo pathway reveals mechanisms of kinase-phosphatase interactions. Sci Signal. 2013;6:rs15.

21. Ye J, Shi H, Shen Y, Peng C, Liu Y, Li C, et al. PP6 controls T cell development and homeostasis by negatively regulating distal TCR signaling. J Immunol. 2015;194:1654-64.

22. Chen J, Peterson RT, Schreiber SL. Alpha 4 associates with protein phosphatases 2A, 4, and 6. Biochem Biophys Res Commun. 1998;247:827-32.

23. Yan S, Xu Z, Lou F, Zhang L, Ke F, Bai J, et al. NF-kappaBinduced microRNA-31 promotes epidermal hyperplasia by repressing protein phosphatase 6 in psoriasis. Nat Commun. 2015;6:7652.

24. Sutton A, Immanuel D, Arndt KT. The SIT4 protein phosphatase functions in late $\mathrm{G} 1$ for progression into $\mathrm{S}$ phase. Mol Cell Biol. 1991;11:2133-48.

25. Chen F, Archambault V, Kar A, Lio P, D'Avino PP, Sinka R, et al Multiple protein phosphatases are required for mitosis in Drosophila. Curr Biol. 2007;17:293-303.

26. Zeng K, Bastos RN, Barr FA, Gruneberg U. Protein phosphatase 6 regulates mitotic spindle formation by controlling the T-loop phosphorylation state of Aurora A bound to its activator TPX2. J Cell Biol. 2010;191:1315-32.

27. Douglas P, Zhong J, Ye R, Moorhead GB, Xu X, Lees-Miller SP. Protein phosphatase 6 interacts with the DNA-dependent protein kinase catalytic subunit and dephosphorylates gamma-H2AX. Mol Cell Biol. 2010;30:1368-81.

28. Hu MW, Wang ZB, Teng Y, Jiang ZZ, Ma XS, Hou N, et al. Loss of protein phosphatase 6 in oocytes causes failure of meiosis II exit and impaired female fertility. J Cell Sci. 2015;128:3769-80.

29. Hu MW, Meng TG, Jiang ZZ, Dong MZ, Schatten H, Xu X, et al. Protein phosphatase 6 protects prophase i-arrested oocytes by safeguarding genomic integrity. PLoS Genet 2016;12:e1006513.

30. Qi ST, Wang ZB, Ouyang YC, Zhang QH, Hu MW, Huang X, et al. Overexpression of SETbeta, a protein localizing to centromeres, causes precocious separation of chromatids during the first meiosis of mouse oocytes. J Cell Sci. 2013;126:1595-603.

31. Peters AH, Plug AW, van Vugt MJ, de Boer P. A drying-down technique for the spreading of mammalian meiocytes from the male and female germline. Chromosome Res. 1997;5:66-8.

32. Bellve AR, Cavicchia JC, Millette CF, O'Brien DA, Bhatnagar YM, Dym M. Spermatogenic cells of the prepuberal mouse. Isolation and morphological characterization. J Cell Biol. 1977;74:68-85.

33. Sadate-Ngatchou PI, Payne CJ, Dearth AT, Braun RE. Cre recombinase activity specific to postnatal, premeiotic male germ cells in transgenic mice. Genesis 2008;46:738-42.

34. Ahmed EA, de Rooij DG. Staging of mouse seminiferous tubule cross-sections. Methods Mol Biol. 2009;558:263-77.

35. Zickler D, Kleckner N. Meiotic chromosomes: integrating structure and function. Annu Rev Genet. 1999;33:603-754.

36. Neale MJ, Keeney S. Clarifying the mechanics of DNA strand exchange in meiotic recombination. Nature 2006;442:153-8.

37. Hunter N, Borner GV, Lichten M, Kleckner N. Gamma-H2AX illuminates meiosis. Nat Genet 2001;27:236-8. 
38. Wang H, Wang M, Wang H, Bocker W, Iliakis G. Complex H2AX phosphorylation patterns by multiple kinases including ATM and DNA-PK in human cells exposed to ionizing radiation and treated with kinase inhibitors. J Cell Physiol. 2005;202:492-502.

39. Barchi M, Mahadevaiah S, Di Giacomo M, Baudat F, de Rooij DG, Burgoyne PS, et al. Surveillance of different recombination defects in mouse spermatocytes yields distinct responses despite elimination at an identical developmental stage. Mol Cell Biol. 2005;25:7203-15.

40. Zhu M, Zhao H, Limbo O, Russell P. Mre11 complex links sister chromatids to promote repair of a collapsed replication fork. Proc Natl Acad Sci USA. 2018;115:8793-8.

41. Cousineau I, Abaji C, Belmaaza A. BRCA1 regulates RAD51 function in response to DNA damage and suppresses spontaneous sister chromatid replication slippage: implications for sister chromatid cohesion, genome stability, and carcinogenesis. Cancer Res 2005;65:11384-91.

42. Baudat F, Imai $\mathrm{Y}$, de Massy B. Meiotic recombination in mammals: localization and regulation. Nat Rev Genet. 2013;14: 794-806.

43. Guillon H, Baudat F, Grey C, Liskay RM, de Massy B. Crossover and noncrossover pathways in mouse meiosis. Mol Cell 2005; 20:563-73.

44. Szekvolgyi L, Ohta K, Nicolas A. Initiation of meiotic homologous recombination: flexibility, impact of histone modifications, and chromatin remodeling. Cold Spring Harb Perspect Biol. 2015;7:a016527.

45. Lee HS, Park JH, Kim SJ, Kwon SJ, Kwon J. A cooperative activation loop among SWI/SNF, gamma-H2AX and $\mathrm{H} 3$ acetylation for DNA double-strand break repair. EMBO J. 2010;29:1434-45.

46. Kim Y, Fedoriw AM, Magnuson T. An essential role for a mammalian SWI/SNF chromatin-remodeling complex during male meiosis. Development 2012;139:1133-40.

47. Rea S, Eisenhaber F, O'Carroll D, Strahl BD, Sun ZW, Schmid M, et al. Regulation of chromatin structure by site-specific histone H3 methyltransferases. Nature 2000;406:593-9.

48. Di Agostino S, Fedele M, Chieffi P, Fusco A, Rossi P, Geremia R, et al. Phosphorylation of high-mobility group protein A2 by Nek2 kinase during the first meiotic division in mouse spermatocytes. Mol Biol Cell. 2004;15:1224-32.
49. Ninomiya-Tsuji J, Kishimoto K, Hiyama A, Inoue J, Cao Z, Matsumoto K. The kinase TAK1 can activate the NIK-I kappaB as well as the MAP kinase cascade in the IL-1 signalling pathway. Nature 1999;398:252-6.

50. Zhou J, Fan Y, Zhong J, Huang Z, Huang T, Lin S, et al. TAK1 mediates excessive autophagy via p38 and ERK in cisplatininduced acute kidney injury. J Cell Mol Med. 2018;22:2908-21.

51. Di Agostino S, Rossi P, Geremia R, Sette C. The MAPK pathway triggers activation of Nek2 during chromosome condensation in mouse spermatocytes. Development 2002;129:1715-27.

52. Hammond D, Zeng K, Espert A, Bastos RN, Baron RD, Gruneberg $\mathrm{U}$, et al. Melanoma-associated mutations in protein phosphatase 6 cause chromosome instability and DNA damage owing to dysregulated Aurora-A. J cell Sci. 2013;126:3429-40.

53. Handel MA, Schimenti JC. Genetics of mammalian meiosis: regulation, dynamics and impact on fertility. Nat Rev Genet. 2010;11:124-36.

54. Jan SZ, Hamer G, Repping S, de Rooij DG, van Pelt AM, Vormer TL. Molecular control of rodent spermatogenesis. Biochim Biophys Acta 2012;1822:1838-50.

55. Kim KP, Mirkin EV. So similar yet so different: the two ends of a double strand break. Mutat Res. 2018;809:70-80.

56. Xu Z, Song Z, Li G, Tu H, Liu W, Liu Y, et al. H2B ubiquitination regulates meiotic recombination by promoting chromatin relaxation. Nucleic Acids Res. 2016;44:9681-97.

57. Sha Y, Zheng L, Ji Z, Mei L, Ding L, Lin S, et al. A novel TEX11 mutation induces azoospermia: a case report of infertile brothers and literature review. BMC Med Genet. 2018;19:63.

58. Silber SJ. Evaluation and treatment of male infertility. Clin Obstet Gynecol. 2000;43:854-88.

59. Venkatesh T, Suresh PS, Tsutsumi R. New insights into the genetic basis of infertility. Appl Clin Genet. 2014;7:235-43.

60. Yang F, Silber S, Leu NA, Oates RD, Marszalek JD, Skaletsky H, et al. TEX11 is mutated in infertile men with azoospermia and regulates genome-wide recombination rates in mouse. EMBO Mol Med. 2015;7:1198-210.

61. Mueller JL, Mahadevaiah SK, Park PJ, Warburton PE, Page DC, Turner JM. The mouse X chromosome is enriched for multicopy testis genes showing postmeiotic expression. Nat Genet 2008; 40:794-9. 